\title{
Early experience treating tricuspid valve endocarditis with a novel extracellular matrix cylinder reconstruction
}

\author{
Marc W. Gerdisch, MD, ${ }^{a}$ W. Douglas Boyd, MD, ${ }^{\mathrm{b}}$ John L. Harlan, MD,${ }^{\mathrm{c}}$ John B. Richardson, Jr, MD, ${ }^{\mathrm{c}}$ \\ Joseph E. Flack III, MD, ${ }^{d}$ Brian A. Palafox, MD, ${ }^{e}$ William E. Johnson III, MD, ${ }^{f}$ Benjamin Sun, MD, ${ }^{g}$ \\ Richard Lee, MD, ${ }^{\mathrm{h}}$ T. Sloane Guy, MD, ${ }^{\mathrm{i}}$ Gyu I. Gang, MD, ${ }^{\mathrm{j}}$ James L. Cox, MD, ${ }^{\mathrm{k}}$ and Vivek Rao, MD, PhD
}

Objective: The short-term outcomes were evaluated in patients treated for tricuspid valve endocarditis using a novel extracellular matrix (ECM) cylinder reconstruction technique.

\begin{abstract}
Methods: Patients with clinically significant tricuspid regurgitation whose valves were not repairable by conventional techniques underwent valve replacement with a cylindrical construct sewn out of CorMatrix ECM (CorMatrix Cardiovascular, Roswell, Ga). The cylinders were sized to the native valve dimensions and attached distally to the papillary muscles using polypropylene sutures and ECM pledgets, and proximally to the annulus using a running suture. Patient data were collected retrospectively.

Results: From November 2011 to October 2013, 12 surgeons performed 19 tricuspid valve cylinder reconstructions in 8 men and 10 women (age range, 19-53 years). Of the 19 patients, 11 had active and 5 had treated endocarditis. One case was robotic-assisted. No deaths occurred, and no new cases of heart block developed. The papillary attachments were disrupted intraoperatively in 1 patient and after 7 days in another; both were successfully revised. A third patient experienced recurrent disruption of the implant at 13 and 22 months and ultimately received a pericardial valve. Fungal infection occurred in 1 cylinder at 6 months; a second ECM cylinder was implanted. Follow-up data were available for 13 patients at 1 to 2 months, 8 at 6 months, and 3 at 12 and 18 months. Other than patients undergoing reoperation, all showed well-functioning tricuspid valves with no to mild regurgitation.
\end{abstract}

Conclusions: Cylinder reconstruction with ECM could be a suitable technique for replacing the tricuspid valve while preserving annuloventricular continuity in patients with infective endocarditis not repairable by conventional techniques. (J Thorac Cardiovasc Surg 2014;148:3042-8)

Isolated tricuspid valve regurgitation secondary to infective endocarditis is most commonly associated with pacemaker infection or intravenous drug abuse, ${ }^{1}$ and the surgical options for treating this pathologic entity are suboptimal. Mechanical and bioprosthetic valves are subject to thrombosis or degenerative calcification, respectively, ${ }^{2-4}$ and no commercially available valve prostheses are specifically designed for the tricuspid valve's distinct anatomy, in

From the Franciscan St Francis Heart Center, ${ }^{a}$ Indianapolis, Ind; University of California, Davis, Medical Center, ${ }^{\mathrm{b}}$ Sacramento, Calif; St Vincent's Hospital East, ${ }^{\mathrm{c}}$ Birmingham, Ala; Baystate Medical Center, ${ }^{\mathrm{d}}$ Springfield, Mass; St Joseph's Hospital, ${ }^{\mathrm{e}}$ Orange, Calif; Mobile Infirmary Medical Center, ${ }^{\mathrm{f}}$ Mobile, Ala; Minneapolis Heart Institute, ${ }^{\mathrm{g}}$ Minneapolis, Minn; St Louis University Hospital Center for Comprehensive Cardiovascular Care, ${ }^{\mathrm{h}}$ St Louis, Mo; Temple University School of Medicine, ${ }^{\mathrm{i}}$ Philadelphia, Pa; Banner Heart Hospital, ${ }^{\mathrm{j}}$ Mesa, Ariz; Division of Cardiothoracic Surgery Emeritus, ${ }^{\mathrm{k}}$ Washington University School of Medicine, Barnes-Jewish Hospital, St Louis, Mo; and Toronto General Hospital, ${ }^{1}$ Toronto, Ontario, Canada.

Professional medical writing services were funded out of an unrestricted grant from CorMatrix Cardiovascular. The authors maintained full freedom of investigation, including control over the study design, interpretation, and critical review, and approval of the manuscript.

Disclosures: Dr Gerdisch: CorMatrix Cardiovascular medical advisory board, equity position, lecturing; On-X Life Technologies consulting and lecturing; Atricure consulting, equity position, lecturing; Medtronic lecturing. Dr Boyd: CorMatrix Cardiovascular medical advisory board and stock options; Titan Medical consulting and stock options; grant from California Institute for Regenerative Medicine. Dr Harlan, CorMatrix Cardiovascular equity position. Dr Richardson, Jr: CorMatrix lecturing and equity position. Dr Palafox: Sorin Carbomedics consulting. Dr Johnson III: Cormatrix Cardiovascular equity position. Dr Sun: Sunshine Heart particular, the elliptical shape of the annulus. ${ }^{5}$ Prosthetic valves in the tricuspid position are frequently associated with heart block ${ }^{6}$ and are susceptible to residual infection. Furthermore, reinfection has been common in the context of the high recidivism rates among intravenous drug abusers. $^{7}$

Tricuspid valve repair using synthetic or biosynthetic materials is also a possible approach to treating isolated

consulting; Thoratec consulting. Dr Guy: Edwards Lifesciences medical advisory board; Medtronic consultant; Ethicon/J\&J consulting; Bionet grant. Dr Gang: CorMatrix Cardiovascular consultant. Dr Cox: consultant, medical advisory board, and equity positions in Adiago, Atricure, CorMatrix Cardiovascular, SentreHeart. Dr Rao: CorMatrix Cardiovascular consultant, lecturing, and equity position; Medtronic consulting and lecturing; Thoratec lecturing. All other authors have nothing to disclose with regard to commercial support.

Read at the 94th Annual Meeting of The American Association for Thoracic Surgery, Toronto, Ontario, Canada, April 26-30, 2014.

Because of a conflict, the final decision on this manuscript was rendered by the Associate Editor.

Received for publication April 9, 2014; revisions received June 16, 2014; accepted for publication June 27, 2014; available ahead of print Aug 29, 2014.

Address for reprints: Marc W. Gerdisch, MD, Franciscan St Francis Heart Center, 5255 E Stop 11 Rd, Suite 200, Indianapolis, IN 46237 (E-mail: mgerdisch@ openheart.net).

$0022-5223$

Copyright (C) 2014 by The American Association for Thoracic Surgery

Open access under CC BY-NC-ND license.

http://dx.doi.org/10.1016/j.jtcvs.2014.06.092 


\section{Abbreviation and Acronym}

$\mathrm{ECM}=$ extracellular matrix

endocarditis $^{8,9}$; however, materials such as polytetrafluoroethylene, polyethylene terephthalate, and glutaraldehyde-fixed pericardium are subject to a foreign body response and degenerative calcification and reinfection. ${ }^{4,10,11}$ New tricuspid bioprostheses that use biocompatible materials in a more functional design are desirable.

In the present report, we assembled the collective, initial clinical experience of 12 independent surgeons using a biocompatible (non-crosslinked), extracellular matrix (ECM)-based material, fashioned into a simple tubular valve similar to the tubular aortic valve originally pioneered by Cox and colleagues, ${ }^{12}$ for tricuspid cylinder reconstruction in the treatment of infective endocarditis.

\section{METHODS}

The present retrospective chart review was determined to be exempt by the Office of Research Services at the Franciscan St Francis Health Center.

\section{Inclusion and Exclusion Criteria}

Each surgeon reviewed the medical records of the adult patients who had undergone ECM tricuspid cylinder reconstruction from 2011 to 2013. All these patients were treated for tricuspid regurgitation secondary to infective endocarditis, with valve pathologic features that were irreparable by conventional techniques.

\section{Operative Preparation}

The patient assessment, preparation, and the specific surgical approaches were according to surgeon preference and clinical judgment. Preoperative echocardiography was used to assess the extent of destruction and to determine the native valve length and diameter. With the exception of a single, robotic-assisted case, all surgical procedures were performed through a median sternotomy, with the patient under general endotracheal anesthesia, and standard cardiopulmonary bypass with bicaval cannulation. The valves were constructed before initiating cardiopulmonary bypass.

\section{Cylinder Construction and Implantation}

To form the cylindrical replacement valve, a sheet of CorMatrix ECM (CorMatrix Cardiovascular, Roswell, Ga) was fashioned into a cylinder with a final diameter sized to match the native annulus. The length of the tube was determined by either the echocardiographic distance from the annulus to the papillary muscle tips or standardized to $120 \%$ of the cylinder's diameter. The seam was sewn with a single-layer, running 4-0 or 50 polypropylene suture (Prolene; Ethicon, Endo-Surgery, Somerville, $\mathrm{NJ}$ ), although in 1 early case (patient 2), polydioxanone suture (Ethicon) was used (not recommended; see the Results and Discussion sections).

Most cases were performed at least partly under cardiac arrest. After crossclamping, myocardial protection, and arrest, all infected tissue, including when necessary, the entire tricuspid valve, partial annulus, and chordae were resected and debrided down to healthy tissue.

For placement of the cylinder (Figures 1 and 2), 3 ventricular attachment points were identified. Because the right ventricular papillary muscle number and position varied, 3 papillary muscle attachments were chosen, roughly equidistant at $120^{\circ}$ apart. The anterior papillary muscle was most consistently positioned and typically acted as the reference point for the choice of the other attachments. The septal chordal insertion might not be discrete, with multiple small muscular sites of attachment. The cylinder suture line was aligned with the septal attachment. Depending on the status of the subvalvular apparatus after debridement and surgeon preference, the attachment was performed at the tips, base, or body of the selected papillary muscles. The attachments were made by placing mattress stitches (usually 4-0 or 5-0 polypropylene or polyester) with or without pledgets (CorMatrix ECM or Teflon; DuPont, Wilmington, Del) in the tissue at each of the papillary attachment points (Figures 1, $A$, and 2, $A$ and $B$ ) and tying them down at 3 evenly spaced points along the distal edge of the ECM cylinder (Figures 1, $B$, and 2, $C$ and $D$ ).

The proximal edge of the cylinder was sutured to the annulus, using running 4-0 or 5-0 polypropylene or polyester suture (Figures 1, C, and $2, E)$. For some valves, the proximal end was folded over to create a $0.5-\mathrm{cm}$ double layer. The seated valves were tested for "neoleaflet" coaptation and competence (Figure 2,F), and the right atrium was closed. After de-airing and weaning from bypass, valve function was confirmed using transesophageal echocardiography before chest closure (Figure 3).

\section{Follow-up and Data Collection}

When possible, the patients were assessed by echocardiography immediately postoperatively and then approximately $1,6,12$, and 18 months postoperatively. The medical records were reviewed to collect demographic, operative, and echocardiographic data. Because of the small number of patients, both overall and per surgeon, the patient data are presented individually, where practical. Descriptive statistics are presented as the mean \pm standard deviation and were calculated using the Microsoft Excel program (Microsoft, Redmond, Wash).

\section{RESULTS}

From November 2011 to October 2013, 19 tricuspid valve cylinder reconstructions were performed in 18 patients by 12 surgeons. Of the 18 patients, 8 were men and 10 were women (mean age, $34.8 \pm 8.8$ years; body mass index, $\left.23.28 \pm 11.8 \mathrm{~kg} / \mathrm{m}^{2}\right)$.

Endocarditis was active in 11 patients, treated in 5, and remote in 2 (9 methicillin-sensitive Staphylococcus aureus, 5 methicillin-resistant $S$ aureus, 1 Propionibacterium acnes, 1 poly-infection with methicillin-sensitive $S$ aureus, and Achromobacter). One case was a reoperation to replace a degenerated prosthetic valve. Of the 18 patients, 16 had a confirmed history of intravenous drug abuse. Septic emboli were present in 14 patients (13 pulmonary, 2 systemic). Other comorbidities and risk factors included encephalopathy $(n=6)$, renal dysfunction $(n=6)$, mild to moderate mitral regurgitation $(n=4)$, hypertension $(n=4)$, history of previous tricuspid valve replacement $(\mathrm{n}=3)$, chronic obstructive pulmonary disease $(\mathrm{n}=1)$, transient ischemic attack $(\mathrm{n}=1)$, and patent foramen ovale $(\mathrm{n}=1)$.

Preoperatively, 6 patients required intravenous vasopressors or inotropic support and 2 had severe right ventricular dilation. One patient required preoperative ventilatory support.

One case (patient 12) was performed using robotic assistance (da Vinci S; Intuitive Surgical, Sunnyvale, Calif). Concurrent procedures included 2 mitral valve repairs, 1 

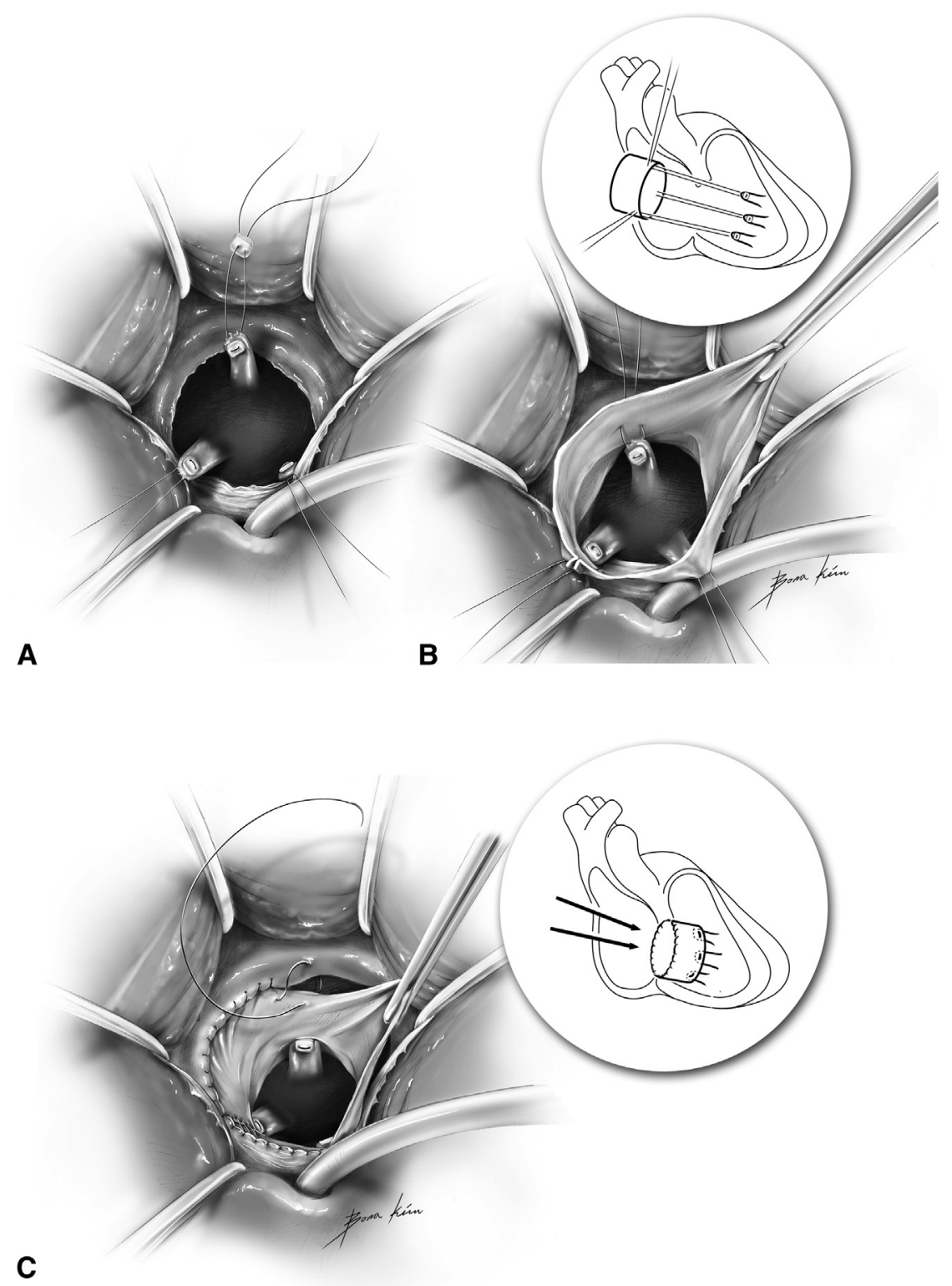

FIGURE 1. Illustration depicting extracellular matrix cylinder implantation technique. A, Mattress sutures are placed in each of the 3 papillary attachment points. B, The extracellular matrix cylinder is tied down at 3 evenly spaced points, with the seam aligned with the septal papillary muscle. C, The proximal edge is sutured to the annulus in a circumferential fashion.

repair of the atrial septal defect, 1 patent foramen ovale closure, 1 explantation of an automated implantable cardioverter defibrillator, 1 dialysis catheter implantation, and 1 repair of an occult right femoral hernia. The pericardium was reconstructed with CorMatrix ECM for pericardial closure in 6 patients.

\section{Adverse Events}

During the follow-up period, no deaths or strokes occurred, and no new-onset patient-prosthesis mismatch was present. Early postoperative events included pulmonary embolism in 2 patients (both with preoperative history of pulmonary embolism) and disseminated intravascular coagulation with acute kidney injury requiring temporary dialysis in 1 patient.

Structural disruptions occurred in 2 early and 1 late case. In 1 case (patient 1), 1 polypropylene suture tore through the papillary muscle intraoperatively, during protamine administration. The patient was reheparinized. On direct inspection, it was determined that all 3 attachments had torn through the papillary tissue. The attachments were revised with pledgeted, braided polyester suture (TiCron; Covidien, New Haven, Conn). In another case (patient 10), all 3 polypropylene attachment sutures had come untied within 7 


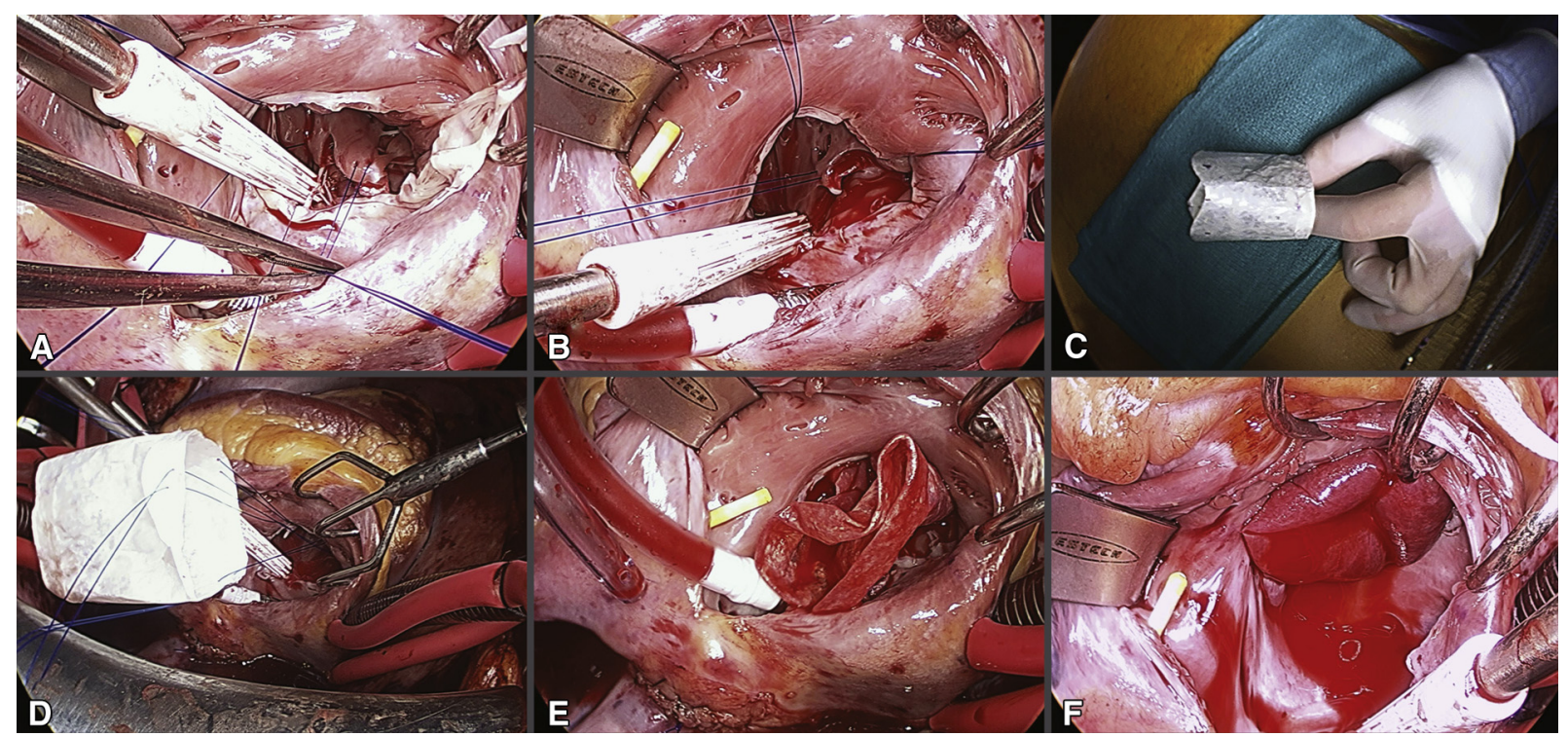

FIGURE 2. Extracellular matrix tricuspid cylinder reconstruction technique. A and B, Placement of sutures in papillary attachment points. C, Extracellular matrix cylinder before implantation. D, The distal edge of the cylinder is tied down to the attachment points. E, The cylinder's proximal edge is sutured circumferentially to the annulus. F, Completed repair showing valve competence under saline insufflation.

days postoperatively. The surgery was revised, and the attachments were tied down with braided suture.

A third patient (patient 2) returned 13 months postoperatively with worsening tricuspid regurgitation secondary to disruption of the cylinder seam and septal papillary attachment. In this patient, polydioxanone sutures had been used for the seam construction and implantation of the cylinder at the first operation. The seam and attachments were revised with polypropylene, but the regurgitation had recurred at 22 months. The cylinder was resected up to the annulus, and a pericardial bioprosthesis was implanted.

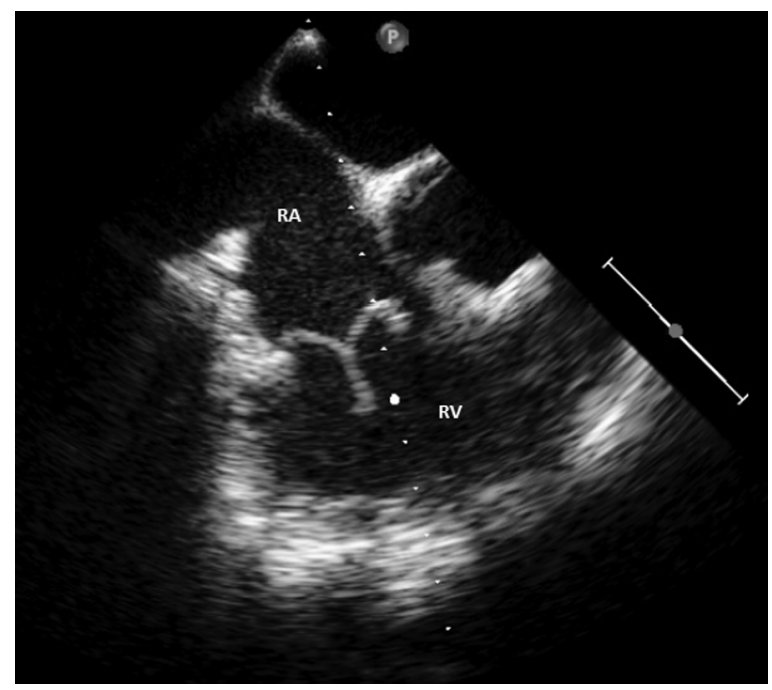

FIGURE 3. Postoperative echocardiogram showing completed valve reconstruction and neoleaflet coaptation. $R A$, Right atrium; $R V$, right ventricle.
Patient 5 returned approximately 6 months postoperatively with a fungal infection of the cylinder. A second ECM cylinder was placed during reoperation.

Patient adherence to the follow-up visit schedule was relatively poor. Echocardiographic follow-up data were successfully collected for 13 of 17 eligible patients at 1 to 2 months, 8 of 10 at 6 months, 3 of 3 at 12 months, and 3 of 3 at 18 months. Other than the patients undergoing reoperation as described, all showed well-functioning tricuspid valves with no to mild regurgitation and no evidence of tricuspid stenosis. The New York Heart Association classification had improved in all evaluated patients, and the left and right ventricular function had remained stable or improved during the follow-up period.

\section{DISCUSSION}

The concept of a tubular prosthetic atrioventricular heart valve was pioneered by James Cox in the late 1980s, based on the hypothesis that native cardiac valves function as simple tubes, with sides that collapse when subjected to external pressure. ${ }^{12}$ That work ultimately led to the development and Food and Drug Administration clearance of the 3F aortic bioprosthesis (Medtronic, Minneapolis, Minn).

Cox and colleagues ${ }^{12}$ tested a number of materials, including an early, investigational preparation of the small intestinal submucosa ECM in the design for both the mitral and the tricuspid positions. The studies showed that the ability of the tubular design to restore normal transprosthetic flow dynamics and stress distribution on the valve leaflets was not dependent on the material used for fabrication. 

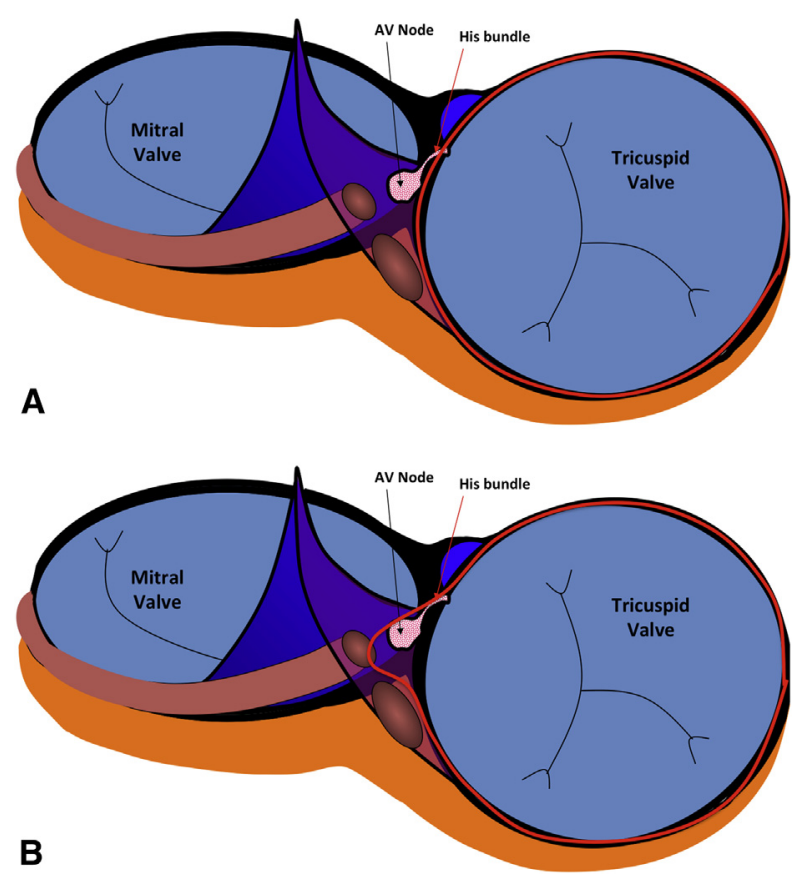

FIGURE 4. Possible placement of sutures in the tricuspid valve annulus during cylinder reconstruction (red lines). A, Recommended placement. At the level of the annulus, the triangle of Koch is avoided and the atrioventricular node-His bundle complex is quite deep, protecting it from interference by the sutures. B, Sutures placed along the tendon of Todaro around the atrioventricular node or placed deeply where the bundle of His traverses into the ventricular septum have the potential to create heart block and should be avoided. $A V$, Atrioventricular.

Crosslinked equine pericardium was ultimately selected as the material for the commercial $3 \mathrm{~F}$ aortic valve product, marking a necessary tradeoff between the benefits of product durability and the known limitations of chemically fixed tissue (ie, degenerative foreign body response, calcification, susceptibility to infection, and the lack of somatic growth potential).

Since then, clinical experience with ECM as a surgical material has increased, and it has now been successfully used in a variety of clinical applications, including aortic annular enlargement, mitral valve repair, myocardial and intraventricular repair, pericardial reconstruction, and vascular repairs. ${ }^{13-20}$

In 2013, Fallon and colleagues ${ }^{21}$ published the results of a small pilot study of the cylindrical tricuspid ECM valve in an ovine model. From the echocardiographic results and gross and microscopic histologic analysis, they found that the cylindrical ECM construct was able to function as a biomechanically sound, bioprosthetic tricuspid valve replacement for $\geq 12$ months, without degeneration or calcification. ${ }^{21}$ Histopathologic examination of explanted constructs showed evidence of progressive endothelialization and constructive tissue remodeling.
The first in-human ECM tricuspid cylinder reconstruction was performed by Wallen and $\mathrm{Rao}^{22}$ at Toronto General Hospital on November 3, 2011. Early results from others' experience with this technique had been presented at medical meetings, ${ }^{23-25}$ but the present study represents the first publication of this technique in full, with collaboration among surgical groups distributed across North America.

\section{Key Lessons}

We noted several interesting technical insights. Although several cases required complete excision of the septal leaflet and/or the entire valve, no cases of heart block occurred. This could represent a substantial advantage over standard prosthetic valve implantation. The cylinder valve construct is sewn circumferentially to the annulus with running suture. Because the suture line does not include the conduction structures in the triangle of Koch, heart block is avoided (Figure 4, A). Heart block could potentially be created if a stitch were placed deep beyond the annulus, at the point at which the bundle of His traverses into the ventricular septum, but this is easily avoided (Figure 4, B).

The use of biodegradable polydioxanone suture in an early case likely contributed to valve seam dehiscence that ultimately necessitated replacement with a bioprosthetic valve. From the clinical experience and the manufacturer's recommendations, until the dynamics of ECM degradation and remodeling are better understood relative to the resorption of biodegradable suture materials, such sutures should not be used for applications in which they must provide structural integrity in the presence of continual biomechanical stress. Furthermore, the findings from animal histologic studies have suggested that polypropylene sutures induce the least-intense inflammatory response and are therefore recommended by the ECM's manufacturer over other nonabsorbable sutures (CorMatrix Cardiovascular; data on file).

In another case, the suture pulled through the tissue where it had been attached at the base of the papillary muscles. To achieve normal inflow, attachment to the papillary tips would be more desirable. In addition to potentially increasing strain on the attachment, the base of the muscle lacks the structural strength of the fibrous tip. Because the septal muscular attachment for the chordae is frequently relatively diffuse, the surgeon must determine it. A dominant fibrous point of connection can be seen. The level of attachment might be more proximate, requiring adjustment of the cylinder length on that side.

A potential advantage of the cylinder construct is maintenance of the annuloventricular continuity, even in cases of total leaflet and chordal disruption. Just as is true with the left ventricle, disconnecting the papillary muscles from their annular connection can lead to late loss of the ventricular conical shape and dilatation. Because all but 1 of the patients in the present report had only recently developed 
regurgitation, only 1 case of chronic right ventricular enlargement was found. It remains to be determined how the dimensions of the cylinder might be altered to remain functional and still promote restoration of ventricular geometry. ${ }^{26}$ In addition, left ventricular function can affect right ventricular papillary muscle position and, therefore, could affect performance of the cylinder. ${ }^{27}$

Finally, the 2 cases of pulmonary embolism were in patients with recent preoperative history of embolism, and it was difficult to determine whether ECM implantation contributed to the postoperative recurrence of this complication. Continued long-term follow-up is necessary to confirm that this technique does not increase the risks of this or other serious complications.

\section{Study Limitations}

The present study was a small, retrospective, exploratory effort in a difficult and poorly adherent patient population, with heterogeneity in surgical techniques. This procedure re-creates the structural components of the valve but also remains dependent on the ventricular geometry and annulopapillary relationship. Thus, successful implantation will likely be guided by some fundamental parameters that remain to be defined. Three of the 4 failures in the present series appeared technique related; 1 actually occurred intraoperatively, and the sharing of this experience will help clarify the methods of addressing these challenges.

Ultimately, our goal is to develop a technique with the ease and reliability of implantation similar to that for current standard replacement valves, and the functional and biocompatibility advantages anticipated with the combination of the cylinder design with ECM. However, the longterm success has yet to be demonstrated.

If we focus on the primary objective of the study, which was to evaluate the overall feasibility of using a cylindrical prosthetic valve made of bioresorbable ECM material in the tricuspid position, we can conclude that patients with tricuspid valve endocarditis not repairable by conventional techniques can be successfully treated with ECM cylinder reconstruction. This approach maintains the annuloventricular continuity important to longterm ventricular function and, by virtue of biocompatibility, it might offer improved longevity in a biologic construct. We will continue to encourage the patients in the present series to return for follow-up evaluation, so that we can monitor and report on their health and progress. From the results of the present series, a formal, prospective clinical study is currently being planned.

The authors thank Molly Miller for coordinating data collection. Jeanne McAdara-Berkowitz, $\mathrm{PhD}$, provided professional assistance with manuscript preparation, which was funded through an unrestricted grant from CorMatrix Cardiovascular. The authors maintained freedom of investigation and control over the study and manuscript.

\section{References}

1. Baraki H, Saito S, Al Ahmad A, Fleischer B, Schmitto J, Haverich A, et al. Surgical treatment for isolated tricuspid valve endocarditis-long-term follow-up at a single institution. Circ J. 2013;77:2032-7.

2. Said SM, Burkhart HM, Schaff HV, Johnson JN, Connolly HM, Dearani JA. When should a mechanical tricuspid valve replacement be considered? J Thorac Cardiovasc Surg. 2014;148:603-8.

3. Rodriguez-Capitan J, Gomez-Doblas JJ, Fernandez-Lopez L, Lopez-Salguero R, Ruiz M, Leruite I, et al. Short- and long-term outcomes of surgery for severe tricuspid regurgitation. Rev Esp Cardiol (Engl Ed). 2013;66:629-35.

4. Garatti A, Nano G, Bruschi G, Canziani A, Colombo T, Frigiola A, et al. Twentyfive year outcomes of tricuspid valve replacement comparing mechanical and biologic prostheses. Ann Thorac Surg. 2012;93:1146-53.

5. Bateman MG, Quill JL, Hill AJ, Iaizzo PA. The clinical anatomy and pathology of the human atrioventricular valves: implications for repair or replacement. $J$ Cardiovasc Transl Res. 2013;6:155-65.

6. Kratz JM, Crawford FAJ, Stroud MR, Appleby DCJ, Hanger KH. Trends and results in tricuspid valve surgery. Chest. 1985;88:837-40.

7. Miro JM, Moreno A, Mestres CA. Infective endocarditis in intravenous drug abusers. Curr Infect Dis Rep. 2003;5:307-16.

8. Shinn SH, Schaff HV. Evidence-based surgical management of acquired tricuspid valve disease. Nat Rev Cardiol. 2013;10:190-203.

9. Sultan FA, Moustafa SE, Tajik J, Warsame T, Emani U, Alharthi M, et al. Rheumatic tricuspid valve disease: an evidence-based systematic overview. J Heart Valve Dis. 2010;19:374-82.

10. Buzzatti N, Iaci G, Taramasso M, Nisi T, Lapenna E, De Bonis M, et al. Longterm outcomes of tricuspid valve replacement after previous left-side heart surgery. Eur J Cardiothorac Surg. 2014;46:713-9.

11. Li X, Guo Y, Ziegler KR, Model LS, Eghbalieh SD, Brenes RA, et al. Curren usage and future directions for the bovine pericardial patch. Ann Vasc Surg. 2011;25:561-8.

12. Cox JL, Ad N, Myers K, Gharib M, Quijano RC. Tubular heart valves: a new tissue prosthesis design-preclinical evaluation of the $3 \mathrm{~F}$ aortic bioprosthesis. $J$ Thorac Cardiovasc Surg. 2005;130:520-7.

13. Gerdisch MW, Akinwande AO, Matheny RG. Use of a novel acellular xenograft as a patch for aortic annular enlargement during aortic valve replacement. Innovations. 2010;5:60-2.

14. Gerdisch MW, Shea RJ, Barron MD. Clinical experience with CorMatrix ECM in the surgical treatment of mitral valve disease. J Thorac Cardiovasc Surg. 2014; 148:1370-8.

15. Eckhauser AW, Hannon D, Molitor M, Scaife E, Gruber PJ. Repair of traumatic aortoinnominate disruption using CorMatrix. Ann Thorac Surg. 2013;95: e99-101.

16. Quarti A, Nardone S, Colaneri M, Santoro G, Pozzi M. Preliminary experience in the use of an extracellular matrix to repair congenital heart diseases. Interact Cardiovasc Thorac Surg. 2011;13:569-72.

17. Sundermann SH, Rodriguez Cetina Biefer H, Emmert MY, Falk V. Use of extracellular matrix materials in patients with endocarditis. Thorac Cardiovasc Surg. 2014;62:76-9.

18. Yanagawa B, Rao V, Yau TM, Cusimano RJ. Initial experience with intraventricular repair using CorMatrix extracellular matrix. Innovations (Phila). 2013;8: 348-52.

19. Yanagawa B, Rao V, Yau TM, Cusimano RJ. Potential myocardial regeneration with CorMatrix ECM: a case report. J Thorac Cardiovasc Surg. 2014;147:e41-3.

20. Stelly M, Stelly TC. Histology of CorMatrix bioscaffold 5 years after pericardial closure. Ann Thorac Surg. 2013;96:e127-9.

21. Fallon AM, Goodchild TT, Cox JL, Matheny RG. In vivo remodeling potential of a novel bioprosthetic tricuspid valve in an ovine model. J Thorac Cardiovasc Surg. 2014;148:333-40.

22. Wallen J, Rao V. Extensive tricuspid valve repair after endocarditis using CorMatrix extracellular matrix. Ann Thorac Surg. 2014;97:1048-50.

23. Boyd WD, Young JN, Cox JL, Bommer WJ, Matheny RJ. Heart valve regeneration with extracellular matrix bioscaffolds: a new surgical technique. Presented at the 17th World Congress of Cardiology Annual Scientific Sessions, 2012.

24. Boyd WD, Cox JL, Fallon AM, Young JN, Matheny RG. Complete tricuspid valve regeneration: a novel minimally invasive surgical technique and new 
surgical paradigm. Presented at the 13 International Society for Minimally Invasive Cardiothoracic Surgery Annual Scientific Meeting, 2013.

25. Mumtaz S, Pretorius V, Madani M, Jamieson SW. CorMatrix fashioned tricuspid valve as alternative to valve resection for acute infective endocarditis. Presented at the 93rd Annual Meeting of the American Association for Thoracic Surgery, 2013.

26. Spinner EM, Lerakis S, Higginson J, Pernetz M, Howell S, Veledar E, et al. Correlates of tricuspid regurgitation as determined by 3D echocardiography: pulmonary arterial pressure, ventricle geometry, annular dilatation, and papillary muscle displacement. Circ Cardiovasc Imaging. 2012;5:43-50.

27. Spinner EM, Sundareswaran K, Dasi LP, Thourani VH, Oshinski J, Yoganathan AP. Altered right ventricular papillary muscle position and orientation in patients with a dilated left ventricle. J Thorac Cardiovasc Surg. 2011;141: 744-9.

\section{Discussion}

Dr Damien J. LaPar (Charlottesville, Va). Dr Gerdisch, I would like to thank you very much for sending us the report ahead of time and presenting a very provocative and novel concept for the treatment of tricuspid valve endocarditis, which we all know is a significant problem.

The authors of this report present 19 patients who underwent a novel tricuspid valve replacement using a cylinder technique using CorMatrix. Importantly, only 8 patients had follow-up data available at 6 months, and only 3 patients had follow-up for $\geq 1$ year. There were 3 patients who experienced failure of this de novo valve owing to sutures pulling through the papillary muscles. We have a few questions for you.

First, how were your patients selected? It is not uncommon to be able to prepare the tricuspid valve in the setting of endocarditis. Can you tell us what the total denominator of all the patients who underwent tricuspid valve surgery at your institutions, including those repaired?

When did you elect to use this technique and when did you repair, and when did you decide to perform a conventional tricuspid valve replacement?

Dr Gerdisch. Thank you. Those are all excellent questions.

Unfortunately, I do not have information for all the institutions with respect to how many tricuspid replacements and repairs were performed during the same period. All the valves were deemed irreparable by other methods. I agree that under certain circumstances, a tricuspid valve can well be repaired. These were all deemed not repairable, completely destroyed valves.
In regard to whether other patients received prostheses, I cannot speak to that either. Typically, the factors that influenced the surgeons were active infection, and, in fact, the high recidivism with patients who were intravenous drug abusers.

Dr LaPar. Great. Thank you. My next question is more technical. The failure rate in this study was largely due to papillary muscle rupture or sutures pulling through the annulus. In our experience at the University of Virginia, we had 1 failure due to the Prolene sutures breaking at the level of the annulus on postoperative day 1 , which required a reoperation.

Why do you think this might have occurred, and are you doing anything, particularly now, because you mentioned in your conclusions that you are refining the technique, to secure the valve after your experience here?

Dr Gerdisch. So that suture disruption was at the annulus, is that what you said?

\section{Dr LaPar. Yes.}

Dr Gerdisch. That is even more unusual. We have not seen that. I have not been aware of that actually and thank you for telling us about it.

This, as you know, has been an attempt to accumulate the national experience. Also, you mentioned earlier that we have limited follow-up, and it is true. One of the reasons that we decided to press ahead with a publication was that we realized that people were adopting, and we wanted to have a consensus idea from everyone how they thought the application was going, what they thought we should change about it, and also just to keep track.

As you mentioned, typically, papillary muscle disruption seemed to be the mechanism of failure, and we, at our most recent conversations about this, thought that perhaps there could be a couple of mechanisms obviously. One would be that simply too much tension is there. That limb that detaches might be too short; that perhaps it is better to have a little bit too long than too short when you build the cylinder. Also, it tends to be at the septal papillary muscle, which frequently is not well defined and often one is attaching to the endocardial surface of the heart, and it is more difficult to define how deep to go and how nice a purchase you can achieve there.

We need to continue to have those conversations. I think that making the tube just a little bit more generous in length than short, and also at the annulus, that is the first time we have seen that, but trying to create an annulus of normal dimensions for the patient.

Dr LaPar. Thank you very much for this contribution. 